\title{
TGF- $\beta 1$, in association with the increased expression of connective tissue growth factor, induce the hypertrophy of the ligamentum flavum through the p38 MAPK pathway
}

\author{
YAN-LIN CAO $^{1 *}$, YANG DUAN $^{1 *}$, LI-XIN ZHU $^{1}$, YE-NAN ZHAN ${ }^{2}$, SHAO-XIONG MIN $^{1}$ and AN-MIN JIN ${ }^{1}$ \\ Departments of ${ }^{1}$ Orthopaedic Surgery and ${ }^{2}$ Neurosurgery, Zhujiang Hospital, \\ Southern Medical University, Guangzhou, Guangdong 510282, P.R. China
}

Received November 20, 2015; Accepted May 26, 2016

DOI: 10.3892/ijmm.2016.2631

\begin{abstract}
Hypertrophy of the ligamentum flavum (LF) is one of the key pathomechanisms of lumbar spinal stenosis (LSS). Transforming growth factor (TGF)- $\beta 1$ is abundantly expressed in hypertrophied degenerative LF tissues from LSS. However, the molecular mechanisms underling the association between TGF- $\beta 1$ and LF hypertrophy have not yet been fully elucidated. In this study, we investigated the important role of the mitogen-activated protein kinase (MAPK) pathway in the pathogenesis of LSS by analyzing the expression of connective tissue growth factor (CTGF) and extracellular matrix (ECM) components (collagen I and collagen III) in TGF- $\beta 1$-treated LF cells. Cell growth assay revealed that TGF- $\beta 1$, in association with CTGF, enhanced the the proliferation of LF cells, and we found that TGF- $\beta 1$ also elevated CTGF expression and subsequently enhanced the mRNA expression of collagen I and collagen III. The increased mRNA expression levels of CTGF, collagen I and collagen III were abolished by p38 inhibitors. Both immunofluorescence imaging and western blot analysis of p38 and p-p38 revealed the increased expression and phosphorylation of $\mathrm{p} 38$. Silencing the expression of $\mathrm{p} 38$ by siRNA in LF cells decreased the protein expression of p38, p-p38 and CTGF, as well as the mRNA expression of CTGF, collagen I and collagen III. Taken together, our findings indicate that TGF- $\beta 1$, in association with the increased expression of CTGF, contribute to the homeostasis of the ECM and to the hypertrophy of LF through the p38 MAPK pathway.
\end{abstract}

Correspondence to: Dr Anmin Jin, Department of Orthopaedic Surgery, Zhujiang Hospital, Southern Medical University, 253 Gongye Road, Guangzhou, Guangdong 510282, P.R. China

E-mail: jinanmin2008@163.com; anminjin2014@sina.com

*Contributed equally

Key words: connective tissue growth factor, transforming growth factor- $\beta 1$, mitogen-activated protein kinases, ligamentum flavum, lumbar spinal stenosis

\section{Introduction}

Lumbar spinal stenosis (LSS) is one of the most common spinal disorders affecting the elderly (1). Degenerative changes in the posterior structures of the lumbar spine, such as hypertrophy of the facet joints and ligamentum flavum (LF), in combination with degenerative spondylolisthesis, can contribute to the development of LSS (2). The hypertrophy of the LF has been described in anatomic studies to be 7- to 8-mm-thick in patients with central stenosis, as opposed to the usual $4 \mathrm{~mm}$ or less (2). Although it is agreed that spinal mechanical stress (3) and secreted cytokines (4) from the herniated disk accelerate the hypertrophy of the LF, which contributes to the development of LSS, the detailed underlying mechanisms are not yet fully understood.

Continuous mechanical stress causes degeneration of the $\mathrm{LF}(5,6)$. Common pathological characteristics in the degenerated LF are the loss of elastic fibers and tissue fibrosis, and increased collagen in tissues (6-8). Mechanical stress increases the production of transforming growth factor (TGF)- $\beta 1$ in several cell lines, including LF cells isolated from surgically resected LF $(9,10)$. TGF- $\beta 1$ is a key factor in the pathogenesis of tissue fibrosis (11) and is abundantly expressed in hypertrophied degenerative LF tissues from LSS (12-14). TGF- $\beta 1$ increases collagen expression in LF cells (15). These previous studies suggest that TGF- $\beta 1$ plays an important role in the hypertrophy of the LF and thus in the pathogenesis of LSS. However, the molecular mechanisms underling the association between TGF- $\beta 1$ and LF hypertrophy, particularly the mechanisms underlying the TGF- $\beta 1$-induced increase in collagen expression have not yet been fully elucidated.

Recently, connective tissue growth factor (CTGF) has been shown to have an increased expression in hypertrophied lumbar LF and to be involved in the hypertrophy of the LF (16). CTGF is a pro-fibrotic factor involved in the fibrotic process, such as cell proliferation, migration, adhesion and extracellular matrix (ECM) accumulation (17). CTGF has also been reported to be involved in the biological activities of TGF- $\beta 1$. For example, TGF- $\beta 1$, in association with CTGF, has been shown to regulate cell proliferation and the synthesis of ECM components (16-18). TGF- $\beta 1$ also induces the mRNA expression of CTGF in human skin fibroblasts (19). TGF- $\beta 1$ is also a well-known inducer of ECM components, such as collagen 
and fibronectin (20). In the presence of CTGF neutralizing antibody (NA), the pro-fibrogenic effects of TGF- $\beta 1$, such as collagen deposition and anchorage-independent growth are attenuated in fibroblasts (20). Additionally, mitogen-activated protein kinases (MAPKs) have been reported to be involved in the regulation of the expression of CTGF $(21,22)$. However, whether the expression of CTGF is regulated by TGF- $\beta 1$ in LF cells and whether it is involved in the hypertrophy of the LF though the MAPK pathway remains unknown.

In this study, we examined the viability of cultured human LF cells, the roles of TGF- $\beta 1 / C T G F$ in the proliferation of LF cells and LF hypertrophy, as well as the role of the MAPK pathway in the pathogenesis of LSS by measuring the expression of CTGF and ECM components (collagen I and collagen III) in TGF- $\beta 1$-treated LF cells obtained from LF tissues of patients who treated with posterior pedicle fixation for lumbar fracture or with a standard nucleotomy for lumbar disc herniation using the Love method.

\section{Materials and methods}

Samples. Specimens from 13 patients, who were treated with posterior pedicle fixation for lumbar fracture or with a standard nucleotomy for lumbar disc herniation using the Love method at Zhujiang Hospital of Southern Medical University, Guangzhou, China, were collected. Informed consent was obtained from each patient, and this study was approved by the Ethics Committee of Southern Medical University.

Cell isolation and culture. The cells were isolated from the LF tissues as previously described $(23,24)$. Briefly, the specimens were minced with microdissection scissors under aseptic conditions and washed extensively with phosphate-buffered saline (PBS) to remove the blood component. The minced tissue was digested at $37^{\circ} \mathrm{C}$ for $60 \mathrm{~min}$ with $0.2 \%$ type I collagenase (Sigma-Aldrich, St. Louis, MO, USA) in serumfree Dulbecco's modified Eagle's medium (DMEM; Gibco, Sydney, Australia). The collagenase-treated ligament chips were washed with serum-containing DMEM to inhibit collagenase activity. The cells were then filtered through a sterile nylon mesh filter (75 $\mu \mathrm{m}$ pore size), and placed in $35-\mathrm{mm}$ Petri dishes at a density of approximately $5 \times 10^{4}$ cells $/ \mathrm{ml}$ in DMEM supplemented with $10 \%$ fetal calf serum (Gibco). The cultures were incubated at $37^{\circ} \mathrm{C}$ in a humidified atmosphere, air $95 \%$ and $\mathrm{CO}_{2} 5 \%$. The medium was changed at 2-day intervals, and the explants were examined daily for cell outgrowth using an inverted light microscope (IX83; Olympus, Tokyo, Japan). The outgrown cells were harvested before confluence and subcultured after trypsinization with $0.2 \%$ trypsin $/ 0.02 \%$ ethylenediaminetetraacetic acid (EDTA). The cells at the third-fifth passage were used for the experiments. Immunofluorescence staining for collagen I and III, and fibronectin was used to identify the phenotype of the cultured LF cells.

Viability of cultured LF cells. The viability of the LF cells was evaluated using the 3-(4,5-dimethylthiazol-2-y1)-2,5-diphenyltetrazolium bromide) (MTT) (Sigma-Aldrich) colorimetric assay, that is based on the reduction of formazan crystals by living cells (25). Briefly, LF cells at passages 1,3 , and 5 were seeded in 96 -well tissue culture plates at $2 \times 10^{4}$ cells/well and incubated at $37^{\circ} \mathrm{C}$ under $5 \% \mathrm{CO}_{2}$ for $0,24,48$ and $72 \mathrm{~h}$. The cells was then washed with PBS and subsequently incubated in $100 \mu \mathrm{l}$ of $5 \mathrm{mg} / \mathrm{ml}$ MTT solution (Invitrogen Life Technologies, Carlsbad, CA, USA) for $3 \mathrm{~h}$. MTT was converted into purple colored formazan in living cells, which was then solubilized with dimethyl sulfoxide (DMSO) (Invitrogen) and the absorbance of the solution was measured at $450 \mathrm{~nm}$ using a microplate reader (Thermo Plate; Rayto Life and Analytical Science Co., Ltd., Shenzhen, China).

Effect of TGF- $\beta 1 / C T G F$ on LF cells. To examine the biological response of human LF cells to TGF- $\beta 1 / C T G F$, the LF cell cultures were treated with $3 \mathrm{ng} / \mathrm{ml}$ TGF- $\beta 1$ or $50 \mathrm{ng} / \mathrm{ml} \mathrm{CTGF}$ (R\&D Systems, Minneapolis, MN, USA) in the absence or presence of CTGF NAs (1:500) for $24 \mathrm{~h}$. The proliferation of the LF cells was first examined by MTT assay, and the mRNA expression levels of CTGF, collagen I and collagen III were then detected by reverse transcription-quantitative polymerase chain reaction (RT-qPCR), and the protein expression of CTGF in the cell lysate was detected by western blot analysis.

Determination of the role of the MAPK pathway. To investigate the role of the MAPK pathway in the TGF- $\beta 1$-induced expression of CTGF, collagen I and collagen III, the LF cell cultures were treated with various MAPK inhibitors including, the JNK inhibitor, SP600125 $(10 \mu \mathrm{M})$, the ERK inhibitor, PD985059 $(10 \mu \mathrm{M})$, and the p38 inhibitor, SB203580 $(100 \mu \mathrm{M})$, (all from Sigma-Aldrich). The cells were pre-treated with the indicated MAPK inhibitors for $1 \mathrm{~h}$, and were then treated with $3 \mathrm{ng} / \mathrm{ml}$ of TGF- $\beta 1$ for $24 \mathrm{~h}$. The mRNA expression levels of CTGF, collagen I and collagen III were then detected by RT-qPCR.

In addition, to further confirm the role of $\mathrm{p} 38$, we examined the expression of p38 and p-p38 in the cells following treatment with $3 \mathrm{ng} / \mathrm{ml}$ TGF- $\beta 1$ for 2,4 , and $6 \mathrm{~h}$ by immunofluorescence staining, and examined the protein expression of p38 and p-p38 in the cells following treatment with $3 \mathrm{ng} / \mathrm{ml}$ TGF- $\beta 1$ for $30 \mathrm{~min}, 1,2$, and $3 \mathrm{~h}$ by western blot analysis.

Validation of the critical role of p38 using p38 siRNA. The involvement of $\mathrm{p} 38$ in the TGF- $\beta 1$-induced expression of CTGF, collagen I and collagen III was further examined using the siRNA-mediated knockdown of p38. For transfection with p38 siRNA or non-targeting negative control (Santa Cruz Biotechnology Inc., Santa Cruz, CA, USA), DharmaFECT reagent (Invitrogen Life Technologies) was used according to the manufacturer's instructions. After $24 \mathrm{~h}$, the culture medium was replaced with fresh supplemented medium, and the cells were cultivated for an additional $24 \mathrm{~h}$ following treatment with $3 \mathrm{ng} / \mathrm{ml}$ TGF- $\beta 1$ for $6 \mathrm{~h}$. The expression levels of p38 and p-p38 were detected by immunofluorescence staining, and the transfection efficiency over time $(0,12,24,36 \mathrm{~h})$ was also validated by RT-PCR (data not shown). The mRNA expression levels of CTGF, collagen I, and collagen III were detected by RT-qPCR. The protein expression of CTGF was detected by western blot analysis.

$R T-q P C R$. Following the afore-mentioned incubation or treatments, total RNA was extracted from the cells using TRIzol reagent (Invitrogen Life Technologies). A total of $2 \mu \mathrm{g}$ of total 

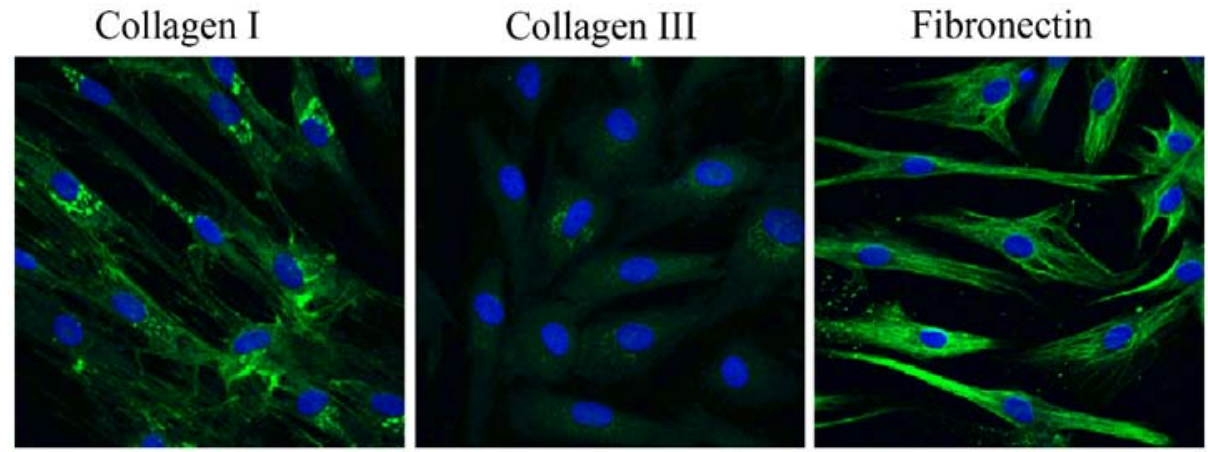

Figure 1. Identification of the phenotype of cultured ligamentum flavum (LF) cells using immunofluorescence staining. Immunofluorescence staining for collagen I and III, and fibronectin in cultured cells; $n=3$ experiments.

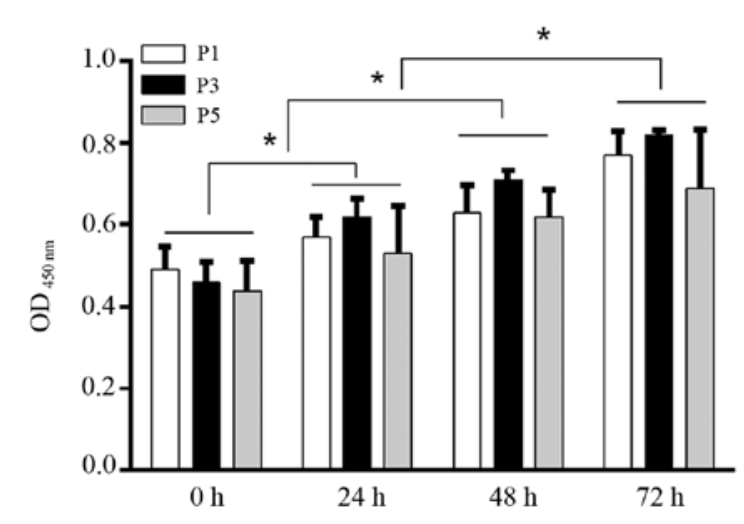

Figure 2. Viability of cultured human lumbar ligamentum flavum (LF) cells was assessed by MTT assay. Although the proliferation of LF cells was enhanced with time, no significant differences among passage (P)1, P3 and P5 cells at $0,24,48$ or $72 \mathrm{~h}$ were detected. $\mathrm{n}=5,{ }^{*} \mathrm{P}<0.05$.

RNA was used to synthesize complementary DNA (cDNA) using M-MLV Reverse Transcriptase (Takara, Dalian, China), and subjected to RT-qPCR using SYBR-Green real-time master mix (Toyobo, Osaka, Japan) with the following primers: 5'-GGAGTGGGTGTGTGACGAG-3' (forward) and 5'-GTC TTCCAGTCGGTAAGCCG-3' (reverse) for CTGF; 5'-AGATC TGAAGTGTGATGACTCAGG-3' (forward) and 5'-CAGAT CACGTCATCGCACAAC-3' (reverse) for collagen I; 5'-ATGT TCCACGGAAACACTGG-3' (forward) and 5'-GGAGAG AAGTCGAAGGAATGC-3' (reverse) for collagen III; CGTGT TGCAGATCCAGACCA (forward) and GCCAGAATGC AGCCTACAGA and (reverse) for p38 siRNA; and 5'-ACACCC ACTCCTCCACCTTT-3' (forward) and 5'-TTACTCCTTGG AGGCCATGT-3' (reverse) for GAPDH. The thermal treatment was $15 \mathrm{~min}$ at $95^{\circ} \mathrm{C}$, followed by 35 cycles of $15 \mathrm{sec}$ at $95^{\circ} \mathrm{C}$, $30 \mathrm{sec}$ at $60^{\circ} \mathrm{C}$, and $30 \mathrm{sec}$ at $72^{\circ} \mathrm{C}$. Gene expression was normalized to the level of GAPDH within each sample using the relative $\Delta \Delta \mathrm{CT}$ method. Gene expression is shown as the expression relative to the control. The data shown are representative of 3 independent experiments.

Western blot analysis. The LF cells were lysed using SDS lysis buffer (Beyotime, Shanghai, China) and centrifuged at $14,000 \mathrm{x} \mathrm{g}$ for $10 \mathrm{~min}$ at $4^{\circ} \mathrm{C}$. Equal amounts of proteins were separated by SDS-PAGE on a $10 \%$ gel and then transferred onto a nitrocellulose membrane, followed by blocking with $5 \%$ bovine serum albumin (BSA) for $1 \mathrm{~h}$ at room tempera- ture. The membrane was then incubated overnight at $4^{\circ} \mathrm{C}$ with rabbit monoclonal antibody specific to CTGF (1:400; ab6992), p-p38 (1:1,000; ab47363), or p38 (1:400; ab27986). All antibodies were purchased from Abcam (Cambridge, MA, USA). Following 3 washes, the membrane was incubated with anti-rabbit IgG conjugated with horseradish peroxidase (A0208; Beyotime) for $1 \mathrm{~h}$ at room temperature. Detection was performed with luminal chemiluminescent systems. Quantitative data were obtained using a computing densitometer and MultiGauge software version 3.0 (Fuji Photo Film Co., Ltd., Tokyo, Japan).

Immunofluorescence staining. The LF cells were rapidly washed once with PBS and fixed with $2 \%$ paraformaldehyde, blocked with $2 \%$ goat serum (GS; C0265; Beyotime) for $30 \mathrm{~min}$, stained with rabbit anti-collagen I (1:100; Ab34710; Abcam), anti-collagen III (1:100; Ab7778; Abcam), anti-fibronectin (1:100; Ab2413; Abcam), p-p38 (1:100), or anti-p38 (1:200) antibodies, and finally visualized with Alexa Fluor 488 goat anti-rabbit antibody (1:150; \#4412; Cell Signaling Technology, Inc., Danvers, MA, USA) for $30 \mathrm{~min}$ at room temperature. Immunofluorescence staining was imaged using a Zeiss LSM 510 laser scanning confocal microscope (Zeiss, Jena, Germany) as previously described (26).

Statistical analysis. All data are expressed as the means \pm standard error of the mean (SEM). One-way analysis of variance (ANOVA) with Fisher's protected LSD post-hoc test was performed to test the difference in densitometeric data. Non-parametric one sample Wilcoxon test was used for the analysis of the results of RT-qPCR. Each experiment was repeated at least 3 times. The statistical significance level was defined as $\mathrm{P}<0.05$.

\section{Results}

Viability of cultured human lumbar LF cells. Human lumbar LF cells were isolated from surgical specimens obtained from 13 patients and cultured. Immunofluorescence staining was used to identify the cell phenotype (Fig. 1). The cultured cells had a typical LF cell phenotype, and uniformly expressed collagen I collagen and fibronectin in each cell, and very few cells expressed type III collagen. Cell proliferation assay revealed that there were no significant differences in cell prolifaration among the LF cell subcultures (passages 1, 3 and 5) at any experimental time point $(0,24,48$, or $72 \mathrm{~h})$ ( $\mathrm{P}>0.05$; Fig. 2$)$. 


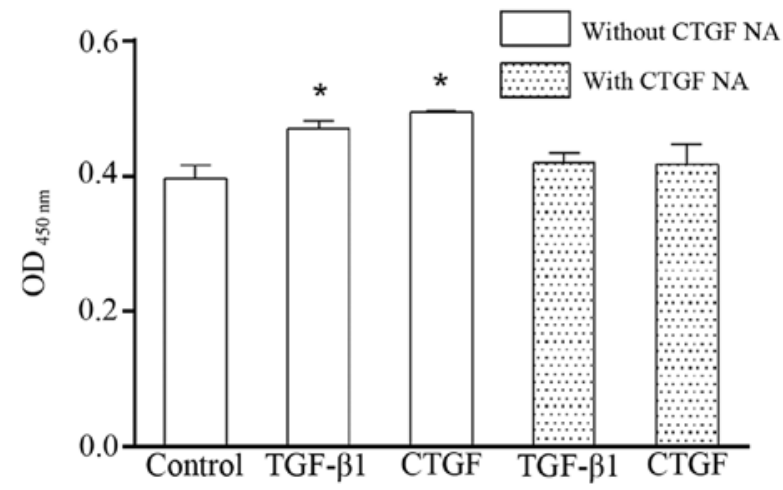

Figure 3. Effects of TGF- $\beta 1 /$ connective tissue growth factor (CTGF) on the proliferation of human lumbar ligmentum flavum (LF) cells. TGF- $\beta 1(3 \mathrm{ng} / \mathrm{ml})$ and CTGF $(50 \mathrm{ng} / \mathrm{ml})$ significantly enhanced the proliferation of human lumbar LF cells, and these effects were abrogated by the addition of CTGF neutralizing antibody (NA; 1:500) for $24 \mathrm{~h} . \mathrm{n}=5$ experiments, ${ }^{*} \mathrm{P}<0.05$ vs. control.

There was no significant difference in cell bioactivities between the individual donors (data not shown). During the 72-h time period, the proliferation of the LF cells was significantly increased with time in each subculture, showing a similar viability with the primary cultured LF cells (Fig. 2).

TGF- $\beta 1 / C T G F$ enhances the proliferation of human lumbar $L F$ cells. Both TGF- $\beta 1$ and CTGF markedly elevated the proliferation of the LF cells (Fig. 3). Of note, the effects of TGF- $\beta 1$ and CTGF on the proliferation of the LF cells were attenuated by CTGF NA, suggesting that TGF- $\beta 1$ associates with CTGF.
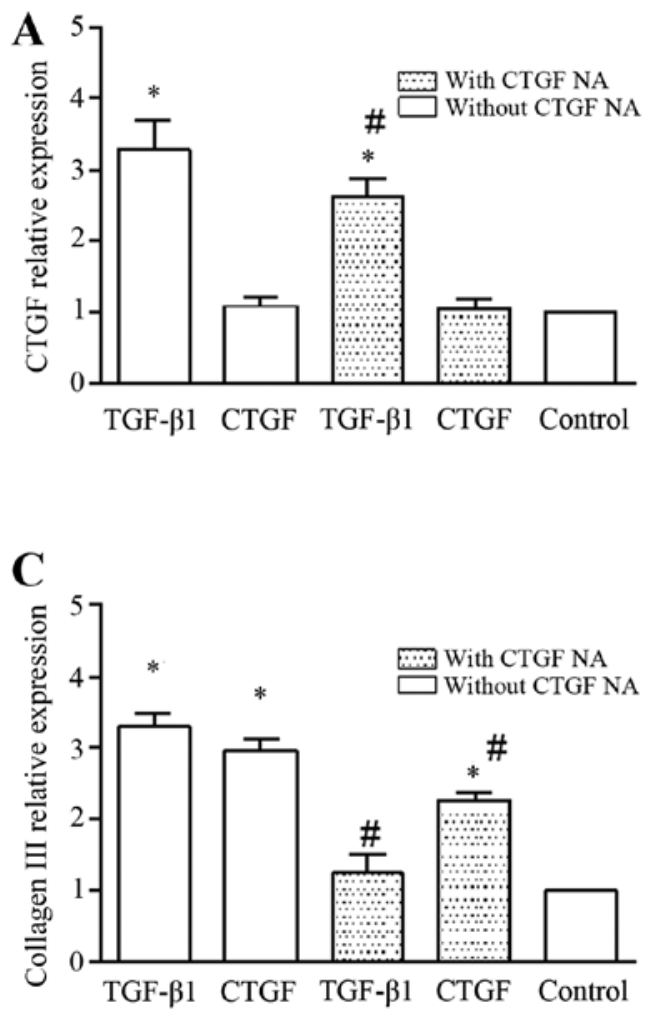

TGF- $\beta 1 / C T G F$ induce the mRNA expression of CTGF, collagen I and collagen III, and the expression of CTGF in cell lysate. TGF- $\beta 1$ increased the mRNA expression of CTGF, and this effect was markedly abolished by CTGF NA (Fig. 4A). To further evaluate the role of TGF- $\beta 1 / \mathrm{CTGF}$ in the hypertrophy of the LF, we determined the mRNA expression of ECM components, such as collagen I (Fig. 4B) and collagen III (Fig. 4C). TGF- $\beta 1 / C T G F$ significantly increased the mRNA expression of collagen I and collagen III. In addition, the presence of CTGF NA abrogated the promoting effects of TGF- $\beta 1 / C T G F$ on the mRNA expression of collagen I and collagen III (Fig. 4B and $\mathrm{C}$ ). We also examined the expression of CTGF in the cell lysate (Fig. 4D). CTGF expression in the cell lysate was increased in the presence of TGF- $\beta 1$ and CTGF, and was diminished by the addition of CTGF NA. Overall, these findings suggest that TGF- $\beta 1 /$ CTGF plays an important role in the hypertrophy of the LF.

In addition, it is worthwhile to note that exogenous CTGF did not enhance the mRNA expression of CTGF in the LF cells (Fig. 4A), but it increased the expression of CTGF in the cell lysate (Fig. 4D), indicating that although CTGF was exogenously expressed in the LF cells, it did not increase the CTGF mRNA level. Importantly, CTGF NA abolished the promoting effects of TGF- $\beta 1$ on CTGF expression.

mRNA expression levels of CTGF, collagen I and collagen III in TGF- $\beta 1$-treated cells are mediated by p38, but not by JNK or ERK. The MAPK inhibitors, namely the JNK inhibitor, SP600125, and the ERK inhibitor, PD985059, did not influence the mRNA expression of CTGF (Fig. 5A), collagen I (Fig. 5B)
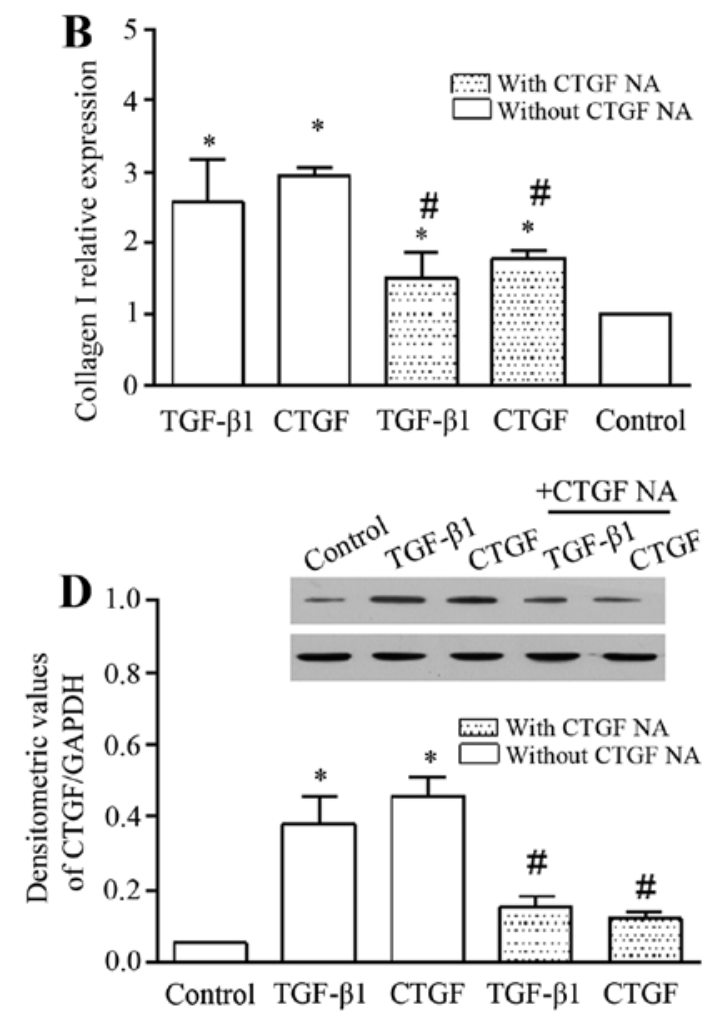

Figure 4. mRNA expression of connective tissue growth factor (CTGF), collagen I and collagen III, and the expression of CTGF in cell lysate. TGF- $\beta 1$ (3 ng/ml) and CTGF (50 ng/ml) increased the mRNA expression of (A) CTGF, (B) collagen I A1, and (C) collagen III A1 significantly. The expression of CTGF in the cell lysate was also significantly increased after $24 \mathrm{~h} . \mathrm{n}=3,{ }^{*} \mathrm{P}<0.05$ vs. control; (D) ${ }^{\#} \mathrm{P}<0.05$ with CTGF vs. without CTGF neutralizing antibody (NA). 

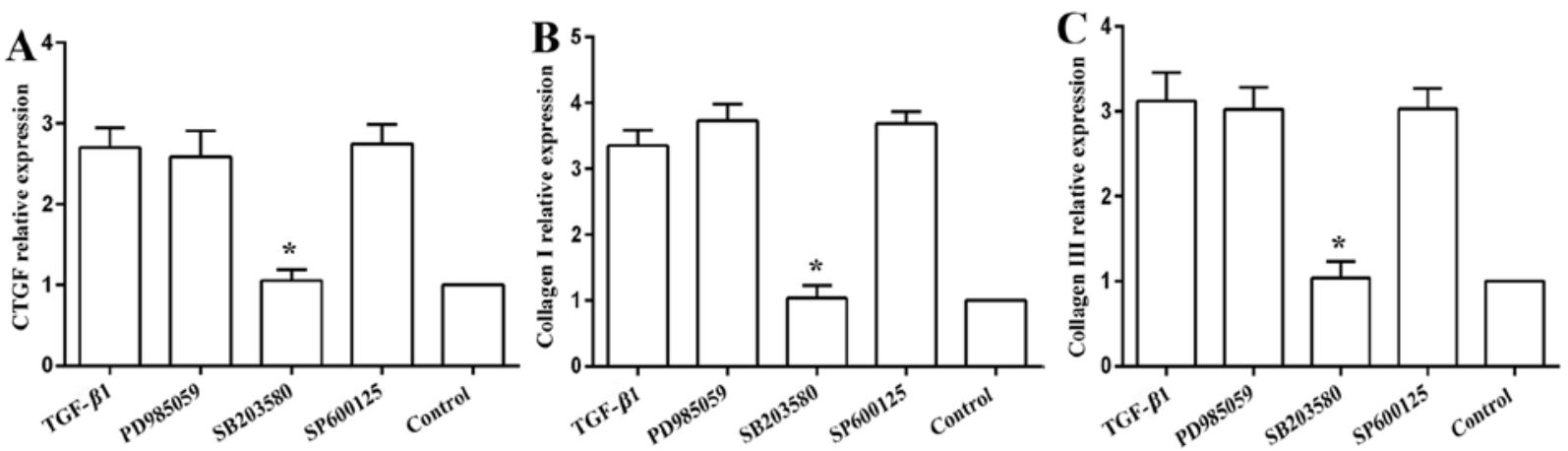

Figure 5. mRNA expressions of connective tissue growth factor (CTGF) collagen I and collagen III in the TGF- $\beta 1$-treated cells in the presence of MAPK inhibitors. Cell were pre-treated with indicated MAPK inhibitors for $1 \mathrm{~h}$, and then with the addition of $3 \mathrm{ng} / \mathrm{ml}$ of TGF- $\beta 1$ for $24 \mathrm{~h}$. TGF- $\beta 1$-increased the mRNA expression of (A) CTGF, (B) collagen I A1, and (C) collagen III A1 and this effect was markedly abrogated by treatment with $100 \mu \mathrm{M}$ of the p38 inhibitor, SB203580, but not by $10 \mu \mathrm{M}$ of the JNK inhibitor, SP600125, or by $10 \mu \mathrm{M}$ of the ERK inhibitor, PD985059; $\mathrm{n}=3$ experiments, ${ }^{*} \mathrm{P}<0.05$ vs. TGF- $\beta 1$.

A
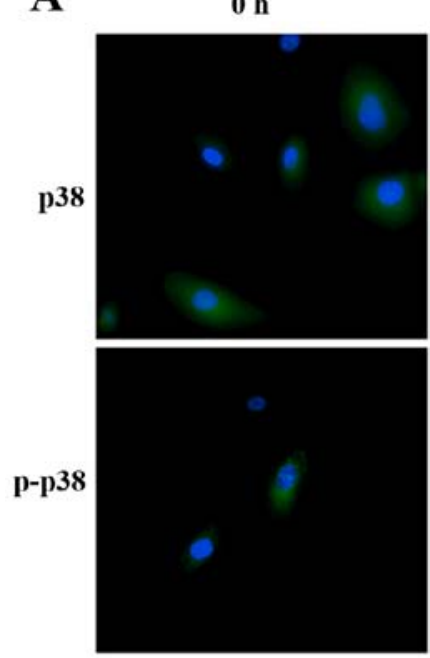

B

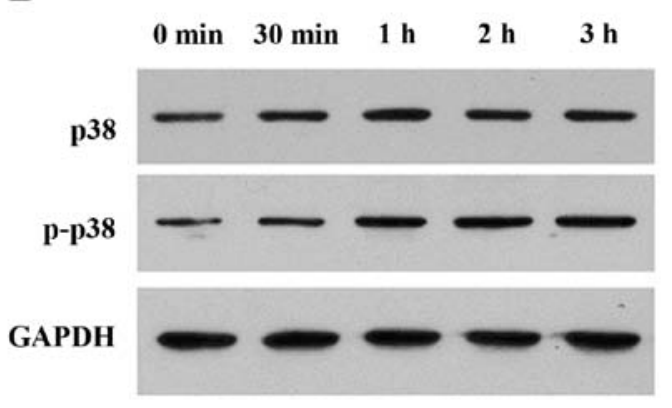

$2 \mathrm{~h}$
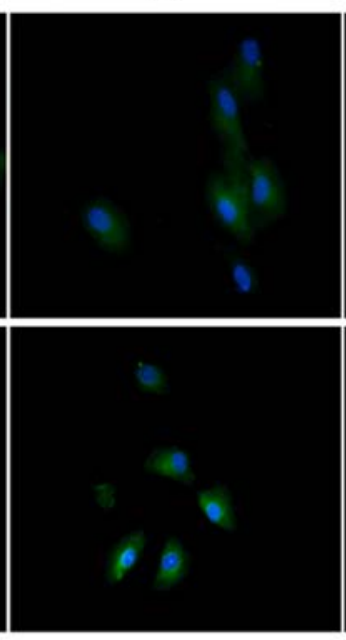

$4 \mathrm{~h}$
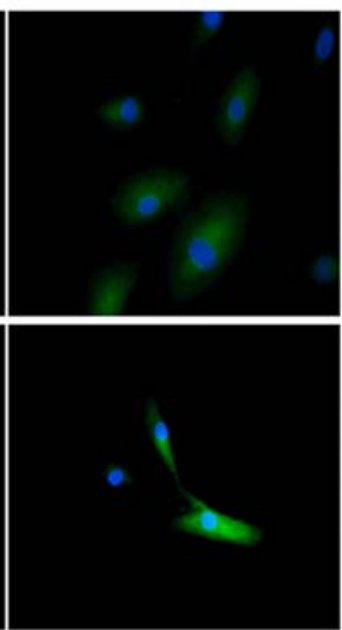

$6 \mathrm{~h}$
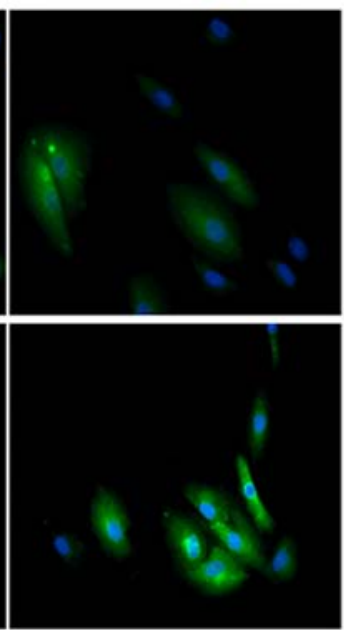

C

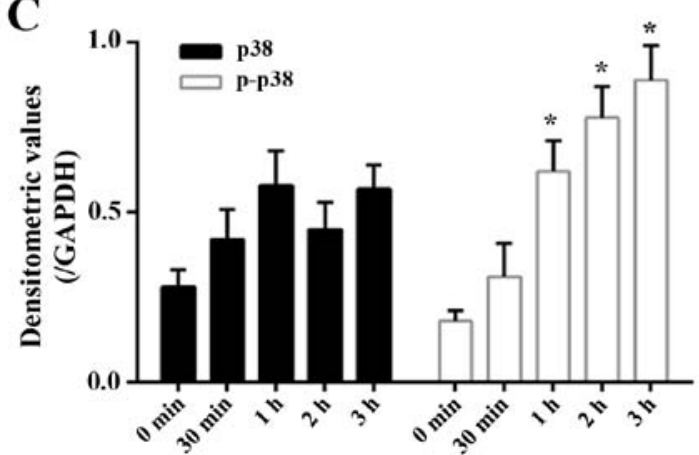

Figure 6. Immunofluorescence staining images and expression of p38 and p-p38 in the TGF- $\beta 1$-treated cells. (A) Immunofluorescence staining for p38 and p-p38 on cells after treated with $3 \mathrm{ng} / \mathrm{ml}$ TGF- $\beta 1$ for 2,4 , and $6 \mathrm{~h}$ were detected. (B) The expression of $\mathrm{p} 38$ and $\mathrm{p}-\mathrm{p} 38$ on cells following treatment with $3 \mathrm{ng} / \mathrm{ml}$ TGF- $\beta 1$ for $30 \mathrm{~min}, 1,2$, and $3 \mathrm{~h}$ detected by western blot analysis. (C) The densitometeric values of results of western blot analysis. $\mathrm{n}=3$ experiments, ${ }^{*} \mathrm{P}<0.05$ vs. control. These results further suggest the important role of $\mathrm{p} 38$ in the TGF- $\beta 1$-induced hypertrophy of the lumbar ligamentum flavum (LF).

or collagen III (Fig. 5C). The p38 MAPK inhibitor, SB203580, abolished the promoting effects of TGF- $\beta 1$ on the mRNA expression of CTGF, collagen I and collagen III, returning the levels close to the baseline levels (Fig. 5).

Expression levels of p38 and p-p38 in TGF- $\beta 1$-treated cells. The immunofluorescence imaging of p38 and p-p38 revealed that their expression and activity was directly related to the duration of TGF- $\beta 1$ treatment (Fig. 6A). TGF- $\beta 1$ gradually and slightly increased the expression of p38 in the LF cells as time progressed ( $\mathrm{P}>0.05$; Fig. $6 \mathrm{~B})$. TGF- $\beta 1$ gradually elevated the expression of p-p38 as time progressed and its expression reached a significant level at $1 \mathrm{~h}$ (Fig. 6B), showing TGF- $\beta 1$ activates the p38 MAPK signaling pathway. 

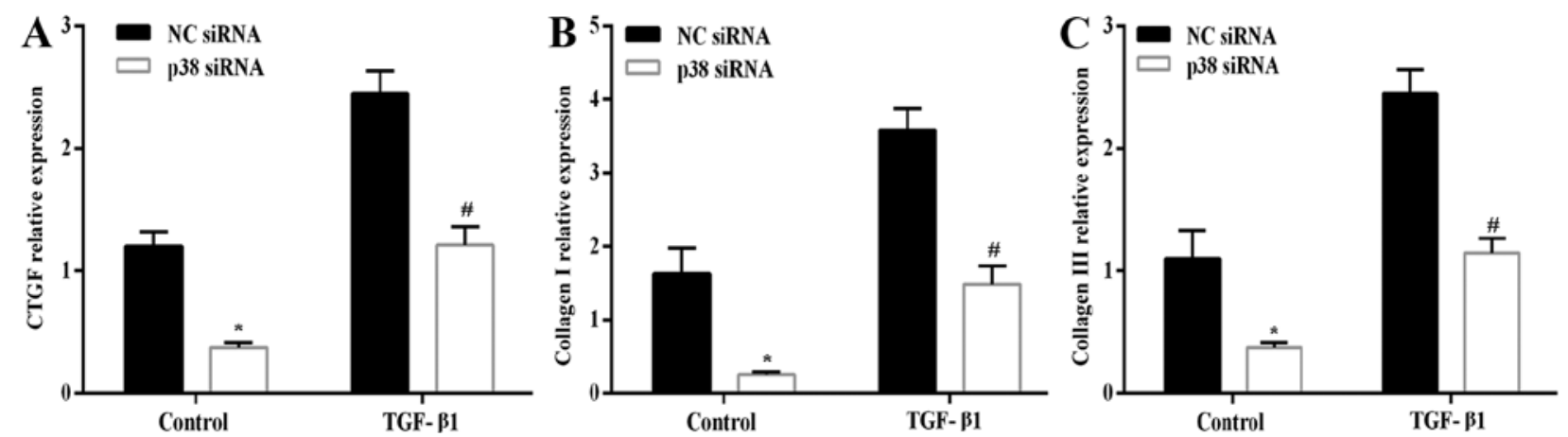

Figure 7. Transfection with $\mathrm{p} 38$ siRNA attenuated the TGF- $\beta 1$-induced mRNA expression of connective tissue growth factor (CTGF), collagen I A1, collagen III A1. The mRNA expression of (A) CTGF, (B) collagen I A1, and (C) collagen III A1 detected by RT-qPCR. "P<0.05 vs. non-targeting negative control (NC siRNA); ${ }^{\#} \mathrm{P}<0.05$ vs. TGF- $\beta 1+\mathrm{NC}$ siRNA. These results have validated that the p38 pathway plays a critical role in TGF- $\beta 1$-induced hypertrophy of the lumbar ligamentum flavum (LF).

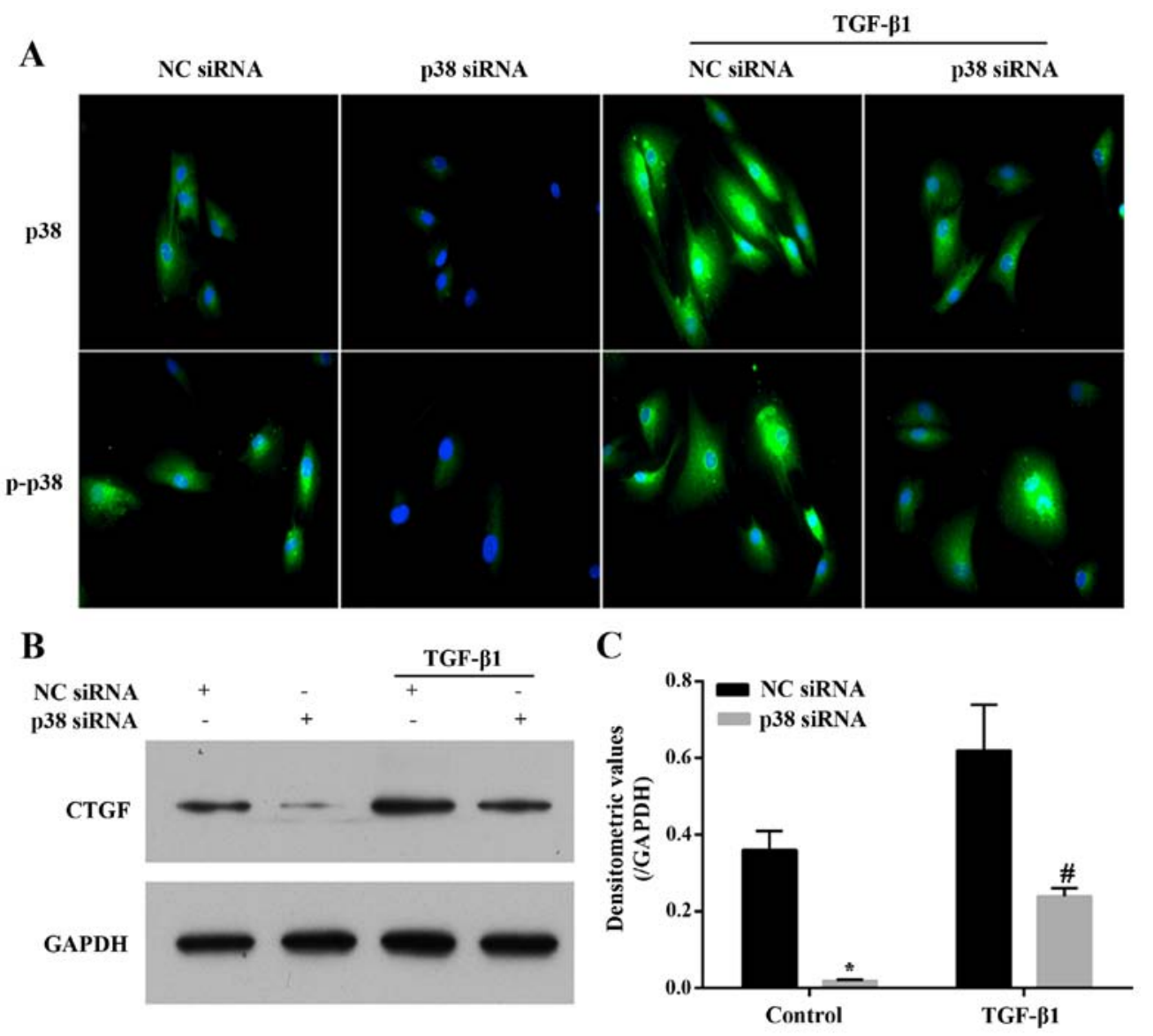

Figure 8. Transfection with p38 siRNA attenuated the TGF- $\beta 1$-induced expression of $\mathrm{p} 38$, p-p38 and connective tissue growth factor (CTGF). (A) The expression of p38 and p-p38 in cells following treatment with $3 \mathrm{ng} / \mathrm{ml}$ TGF- $\beta 1$ for $6 \mathrm{~h}$ was detected by immunofluorescence staining. (B) The expression of CTGF was detected by western blot analysis. (C) The densitometeric values of results of western blot analysis. $n=3,{ }^{*} \mathrm{P}<0.05$ vs. non-targeting negative control (NC siRNA); ${ }^{\#} \mathrm{P}<0.05$ vs. TGF- $\beta 1+\mathrm{NC}$ siRNA. These results have validated that the p38 pathway plays a critical role in TGF- $\beta 1$-induced hypertrophy of the lumbar ligamentum flavum (LF).

Transfection with p38 siRNA abrogates the effects of TGF- $\beta 1$. After silencing the expression of $\mathrm{p} 38$ by $\mathrm{p} 38$ siRNA in the LF cells, the mRNA expression levels of CTGF (Fig. 7A), collagen I (Fig. 7B) and collagen III (Fig. 7C) in the presence or absence of $3 \mathrm{ng} / \mathrm{ml}$ TGF- $\beta 1$ for $6 \mathrm{~h}$ were significantly decreased compared with the NC siRNA-transfected cells. Similarly, the silencing of the expression of p38 in the LF cells significantly diminished the expression and phosphorylation level of $\mathrm{p} 38$, as well as the TGF- $\beta 1$ ( $3 \mathrm{ng} / \mathrm{ml}$ for $6 \mathrm{~h}$ )-induced expression and activity of p38 compared with the NC siRNAtransfected cells (Fig. 8A). The expression of CTGF in the cell lysate exhibited a similar trend with its mRNA expression. TGF- $\beta 1$ ( $3 \mathrm{ng} / \mathrm{ml}$ for $6 \mathrm{~h}$ ) increased the expression of CTGF, and this effect was abrogated by the silencing of p38 (Fig. 8B 
and C). Overall, the results presented above indicate that the p38 MAPK signing pathway plays a critical role in the TGF- $\beta 1$ induced hypertrophy of the LF.

\section{Discussion}

Stenotic LF cells can produce a matrix rich in type I and III collagen and fibronectin (23), and the cultured cells acquire the LF cell phenotype with the uniform expression of collagen I and type III collagen, as well as fibronectin in each cell.

Hypertrophy of the LF plays an important role in the development of LSS (2). Spinal mechanical stress (3) and secreted cytokines (4) from herniated disk accelerate the hypertrophy of the LF. Mechanical stress increases the production of TGF- $\beta 1(9,10)$. The association between TGF- $\beta 1$ and LF hypertrophy has not yet been fully elucidated. In this study, we found that TGF- $\beta 1$ enhanced the expression of CTGF at both the mRNA and protein level, further supporting the existence of an interaction between CTGF and TGF- $\beta 1$, as described in a previous study (27). Furthermore, TGF- $\beta 1$ elevated the mRNA expression of ECM components, including collagen I and III, and this effect was abolished by the CTGF NA, indicating that TGF- $\beta 1$ contributes to the hypertrophy of the LF in association with CTGF. Furthermore, the associations between TGF- $\beta 1$, CTGF and LF hypertrophy are mediated through the p38 MAPK pathway.

Previous studies have demonstrated that TGF- $\beta 1$, in association with CTGF, regulates cell proliferation $(16,18)$. In this study, we found that TGF- $\beta 1$ enhanced the proliferation of LF cells, and this associated with an increase in CTGF expression. However, with the addition of CTGF NA, the promoting effects of TGF- $\beta 1$ on the proliferation of LF cells were abrogated (Fig. 3). Furthermore, TGF- $\beta 1$, in association with CTGF, regulates the synthesis of ECM components $(16,18)$. The increased synthesis of collagen is a major characteristic of LF hypertrophy (10). LF cells have a typical fibroblastlike phenotype, as they express type I and type III collagen and fibronectin, but do not stain positive for osteonectin (23). Normal cells do not synthesize type II collagen (23). Type I and type III collagen have been found to be predominant in human LF (28). In this study, we also observed that TGF- $\beta 1$ increased the mRNA expression of collagen I and collagen III, and this effect was abrogated by CTGF NA, indicating that the TGF- $\beta 1$-induced synthesis of ECM components is associated with CTGF. TGF- $\beta 1$ elevated the expression of CTGF at both the mRNA and protein level (Fig. 4). Therefore, TGF- $\beta 1$, in association with CTGF, contributed to the hypertrophy of the LF.

In general, the effects of TGF- $\beta$ are mediated through the phosphorylation of cytoplasmic R-Smads $(29,30)$. In addition to the activation of Smad signaling, TGF- $\beta 1$ can activate members of the MAPK pathway, as well as other kinases $(31,32)$. Upon stimulation with TGF- $\beta$, the crosstalk between the ERK, p38, JNK and Smad pathways is cell type-specific $(33,34)$. Previous studies have shown the pro-fibrotic activities of p38 and ERK signaling, and the anti-fibrotic activities of JNK signaling (27). The pathway involved in the TGF- $\beta 1$-induced hypertrophy of the LF has not been addressed to date, to the best of our knowledge. In this study, among ERK, p38, and JNK, only the use of the p38 inhibitor abolished the mRNA expression of CTGF, and collagen I and III (Fig. 5), indicating the profibrotic activities of $\mathrm{p} 38$ signaling. We further observed that the expression and phosphorylation level of p38 were enhanced by TGF- $\beta 1$. Following the silencing of p38 MAPK (its efficiency over time was almost the same; data not shown), the expression and phosphorylation level of $\mathrm{p} 38$, as well as the mRNA expression of CTGF, collagen I and collagen III were attenuated correspondingly, as well as the expression of CTGF (Fig. 6). Apparently, the expression of p38 and p-p38 presented in Fig. 6A does not match that shown in Fig. 6B. It is worth noting that the immunofluorescence staining in this study was focused on the cell surface, that should limit the detection of intracellular signaling, but the western blot analysis included all the intracellular and cell surface information. These results further confirm that p38 MAPK is a key mediator of the effects of TGF- $\beta 1$, and the pro-fibrotic activities of p38 signaling.

In conclusion, TGF- $\beta 1$, in association with the increased expression of CTGF, induce the hypertrophy of the LF through the p38 MAPK pathway. Degenerative changes in the posterior structures of the lumbar spine, such as the hypertrophy of the facet joints and LF, in combination with degenerative spondylolisthesis, contribute to the development of LSS (2). Patients with LSS usually present with the typical symptoms of neurogenic claudication and/or lumbar or sacral radiculopathy $(35,36)$. Many patients may also complain of pain when performing activities requiring the extension of the spine. These symptoms may improve with appropriate conservative treatment, although $60-85 \%$ of patients undergo surgical treatments (35). Our observations appear to be important for evaluating the pathomechanisms of LSS, and may prove to be helpful in the diagnosis and prevention of LSS in the early stage, and may also provide an effective alternative to surgery.

\section{Acknowledgements}

This study was supported by funds from the Guangdong Science and Technology plan project (no. 2011B080701018), and the Guangdong Medical Science and Technology Research Fund (no. A2012372).

\section{References}

1. Siebert E, Prüss H, Klingebiel R, Failli V, Einhäupl KM and Schwab JM: Lumbar spinal stenosis: syndrome, diagnostics and treatment. Nat Rev Neurol 5: 392-403, 2009.

2. Botwin KP and Gruber RD: Lumbar spinal stenosis: anatomy and pathogenesis. Phys Med Rehabil Clin N Am 14: 1-15, 2003.

3. Fukuyama S, Nakamura T, Ikeda T and Takagi K: The effect of mechanical stress on hypertrophy of the lumbar ligamentum flavum. J Spinal Disord 8: 126-130, 1995.

4. Behm B, Babilas P, Landthaler M and Schreml S: Cytokines, chemokines and growth factors in wound healing. J Eur Acad Dermatol Venereol 26: 812-820, 2012.

5. Matsumoto Y, Fujiwara T, Imamura R, Okada Y, Harimaya K, Doi T, Kawaguchi K, Okada S, Yamada Y, Oda Y and Iwamoto Y: Hematoma of the ligamentum flavum in the thoracic spine: report of two cases and possible role of the transforming growth factor beta-vascular endothelial growth factor signaling axis in its pathogenesis. J Orthop Sci 18: 347-354, 2013.

6. Maezawa Y, Baba H, Uchida K, Kokubo Y, Kubota C and Noriki S: Ligamentum flavum hematoma in the thoracic spine. Clin Imaging 25: 265-267, 2001.

7. Sairyo K, Biyani A, Goel VK, Leaman DW, Booth R Jr, Thomas J, Ebraheim NA, Cowgill IA and Mohan SE: Lumbar ligamentum flavum hypertrophy is due to accumulation of inflammation-related scar tissue. Spine 32: E340-E347, 2007. 
8. Kosaka H, Sairyo K, Biyani A, Leaman D, Yeasting R, Higashino K, Sakai T, Katoh S, Sano T, Goel VK and Yasui N: Pathomechanism of loss of elasticity and hypertrophy of lumbar ligamentum flavum in elderly patients with lumbar spinal canal stenosis. Spine 32: 2805-2811, 2007.

9. Nakamura T, Okada T, Endo M, Kadomatsu T, Taniwaki T, Sei A, Odagiri H, Masuda T, Fujimoto T, Nakamura T, et al: Angiopoietin-like protein 2 induced by mechanical stress accelerates degeneration and hypertrophy of the ligamentum flavum in lumbar spinal canal stenosis. PLoS One 9: e85542, 2014

10. Nakatani T, Marui T, Hitora T, Doita M, Nishida $K$ and Kurosaka M: Mechanical stretching force promotes collagen synthesis by cultured cells from human ligamentum flavum via transforming growth factor-beta1. J Orthop Res 20: 1380-1386, 2002.

11. Ariel A and Timor O: Hanging in the balance: endogenous anti-inflammatory mechanisms in tissue repair and fibrosis. J Pathol 229: 250-263, 2013.

12. Seko Y, Seko Y, Takahashi N, Shibuya M and Yazaki Y: Pulsatile stretch stimulates vascular endothelial growth factor (VEGF) secretion by cultured rat cardiac myocytes. Biochem Biophys Res Commun 254: 462-465, 1999.

13. Löhr M, Hampl JA, Lee JY, Ernestus RI, Deckert $M$ and Stenzel W: Hypertrophy of the lumbar ligamentum flavum is associated with inflammation-related TGF- $\beta$ expression. Acta Neurochir (Wien) 153: 134-141, 2011.

14. Park JB, Chang H and Lee JK: Quantitative analysis of transforming growth factor-beta 1 in ligamentum flavum of lumbar spinal stenosis and disc herniation. Spine 26: E492-E495, 2001.

15. Chen YT, Wei JD, Wang JP, Lee HH, Chiang ER, Lai HC Chen LL, Lee YT, Tsai CC, Liu CL, et al: Isolation of mesenchymal stem cells from human ligamentum flavum: implicating etiology of ligamentum flavum hypertrophy. Spine 36 : E1193-E1200, 2011.

16. Zhong ZM, Zha DS, Xiao WD, Wu SH, Wu Q, Zhang Y, Liu FQ, and Chen JT: Hypertrophy of ligamentum flavum in lumbar spine stenosis associated with the increased expression of connective tissue growth factor. J Orthop Res 29: 1592-1597, 2011.

17. Brigstock DR: The connective tissue growth factor/cysteine-rich 61/nephroblastoma overexpressed (CCN) family. Endocr Rev 20 189-206, 1999.

18. Taipale J, Miyazono K, Heldin CH and Keski-Oja J: Latent transforming growth factor-beta 1 associates to fibroblast extracellular matrix via latent TGF-beta binding protein. J Cell Biol 124: 171-181, 1994

19. Igarashi A, Okochi H, Bradham DM and Grotendorst GR Regulation of connective tissue growth factor gene expression in human skin fibroblasts and during wound repair. Mol Biol Cell 4 637-645, 1993

20. Abreu JG, Ketpura NI, Reversade B and De Robertis EM: Connective-tissue growth factor (CTGF) modulates cell signalling by BMP and TGF-beta. Nat Cell Biol 4: 599-604, 2002.
21. Chen Z, Gibson TB, Robinson F, Silvestro L, Pearson G, Xu B, Wright A, Vanderbilt C and Cobb MH: MAP kinases. Chem Rev 101: 2449-2476, 2001.

22. Gu J, Liu X, Wang QX, Tan HW, Guo M, Jiang WF and Zhou L: Angiotensin II increases CTGF expression via MAPKs/TGF- $\beta 1 /$ TRAF6 pathway in atrial fibroblasts. Exp Cell Res 318: 2105-2115, 2012.

23. Specchia N, Pagnotta A, Gigante A, Logroscino G and Toesca A: Characterization of cultured human ligamentum flavum cells in lumbar spine stenosis. J Orthop Res 19: 294-300, 2001.

24. Zhong ZM and Chen JT: Phenotypic characterization of ligamentum flavum cells from patients with ossification of ligamentum flavum. Yonsei Med J 50: 375-379, 2009.

25. Mosmann T: Rapid colorimetric assay for cellular growth and survival: application to proliferation and cytotoxicity assays. J Immunol Methods 65: 55-63, 1983.

26. Zeng Y, Adamson RH, Curry FR and Tarbell JM: Sphingosine-1-phosphate protects endothelial glycocalyx by inhibiting syndecan-1 shedding. Am J Physiol Heart Circ Physiol 306: H363-H372, 2014.

27. Leask A and Abraham DJ: TGF-beta signaling and the fibrotic response. FASEB J 18: 816-827, 2004.

28. Yoshida M, Shima K, Taniguchi Y, Tamaki T and Tanaka T: Hypertrophied ligamentum flavum in lumbar spinal canal stenosis. Pathogenesis and morphologic and immunohistochemical observation. Spine 17: 1353-1360, 1992.

29. Feng XH and Derynck R: Specificity and versatility in tgf-beta signaling through Smads. Annu Rev Cell Dev Biol 21: 659-693, 2005.

30. Massagué J: How cells read TGF-beta signals. Nat Rev Mol Cell Biol 1: 169-178, 2000

31. Strand DW, Liang YY, Yang F, Barron DA, Ressler SJ, Schauer IG, Feng XH and Rowley DR: TGF- $\beta$ induction of FGF-2 expression in stromal cells requires integrated smad3 and MAPK pathways. Am J Clin Exp Urol 2: 239-248, 2014

32. Demagny H, Araki T and De Robertis EM: The tumor suppressor Smad4/DPC4 is regulated by phosphorylations that integrate FGF, Wnt, and TGF- $\beta$ signaling. Cell Reports 9: 688-700, 2014.

33. Derynck R and Zhang YE: Smad-dependent and Smadindependent pathways in TGF-beta family signalling. Nature 425 577-584, 2003

34. Javelaud D and Mauviel A: Crosstalk mechanisms between the mitogen-activated protein kinase pathways and Smad signaling downstream of TGF-beta: implications for carcinogenesis. Oncogene 24: 5742-5750, 2005.

35. Binder DK, Schmidt MH and Weinstein PR: Lumbar spinal stenosis. Semin Neurol 22: 157-166, 2002.

36. Omidi-Kashani F, Hasankhani EG and Ashjazadeh A: Lumbar spinal stenosis: who should be fused? an updated review. Asian Spine J 8: 521-530, 2014. 